\title{
DETERMINAN PARTISIPASI DAN PERAN PETANI MUDA DALAM PENGEMBANGAN PERTANIAN RAMAH LINGKUNGAN DI DESA CISONDARI, KECAMATAN CIWIDEY, KABUPATEN BANDUNG, JAWA BARAT
}

\section{DETERMINANT OF PARTICIPATION AND ROLE OF YOUNG FARMER IN ENVIRONMENTALLY FRIENDLY AGRICULTURAL DEVELOPMENT IN CISONDARI VILLAGE, CIWIDEY DISTRICT, BANDUNG REGENCY, WEST JAVA}

\author{
Fitrah Rahmah Insani $^{1}$, Iwan Setiawan ${ }^{2}$, Siska Rasiska $^{3}$ \\ ${ }^{1}$ Program Studi Agribisnis, Fakultas Pertanian Universitas Padjadjaran \\ ${ }^{2}$ Departemen Sosial Ekonomi Pertanian, Fakultas Pertanian Universitas Padjadjaran \\ ${ }^{3}$ Departemen Hama dan Penyakit Tumbuhan, Fakultas Pertanian Universitas Padjadjaran \\ *E-mail: i.setiawan@unpad.ac.id \\ E-mail: fitrahrahmahi@yahoo.com \\ (Diterima 17-04-2018; Disetujui 28-05-2018)
}

\begin{abstract}
ABSTRAK
Pembangunan pertanian dalam dua dekade terakhir diarahkan pada pertanian ramah lingkungan. Desa Cisondari merupakan desa produsen hortikultura berbasis pertanian ramah lingkungan, yang didukung oleh peran pemuda taninya. Pada era globalisasi, tingginya tingkat urbanisasi tidak dapat dihindarkan, khususnya bagi penduduk desa usia muda. Hal ini berdampak pada penurunan jumlah petani muda di desa yang seharusnya menjadi motor penggerak roda pembangunan pertanian. Walaupun demikian, Desa Cisondari menunjukkan gejala yang berbeda, di mana pemuda berperan aktif dalam mengembangkan pertanian ramah lingkungan. Penelitian ini bertujuan untuk mengidentifikasi faktor yang mempengaruhi partisipasi petani muda dalam pengembangan pertanian ramah lingkungan di Desa Cisondari. Penelitian dilakukan melalui pendekatan kuantitatif dengan menggunakan analisis statistik deskriptif. Data diperoleh melalui wawancara terstruktur yang dilakukan terhadap responden yang dipilih dengan teknik simple random sampling. Hasil penelitian menunjukkan bahwa beberapa faktor yang meningkatkan partisipasi petani muda ialah motivasi, inovasi, dan faktor lingkungan. Petani muda berperan dalam berbagai kegiatan pengembangan pertanian berkelanjutan dari mulai tahap perencanaan, pelaksanaan, monitoring hingga tahap evaluasi.
\end{abstract}

Kata Kunci: Pertanian Ramah Lingkungan, Partisipasi Petani Muda, Regenerasi Petani

\section{ABSTRACT}

Agricultural development since the last two decades has been mainstreamed to a more environmentally friendly perspective. Cisondari is a village known for applying environmentally friendly practices in their agriculture. In this globalization era, urbanization is inevitable, especially for rural youths. This situation has impacted agricultural workforce structure in the rural area, threatening its future agriculture. However, Cisondari shows an anomaly condition. Cisondari's agricultural development is highly influenced by the active presence of rural youths. This study aims to identify the determinants of the rural youths' participation in Cisondari's agricultural development. The study applies quantitative methods through descriptive statistics analysis. Data were 
gathered by structured interviews to respondents selected by simple random sampling technique. The results show that the determinants of youths staying in the village are motivation, innovation, and environmental factors. The young farmers are involved in environmentally friendly agricultural practices in many phases ranged from planning, conducting, monitoring, to evaluation.

Keywords: Eco-friendly Farming, Youth Participation, Farmers Regeneration

\section{PENDAHULUAN}

Arah pembangunan pertanian dalam dua dekade terakhir dititikberatkan pada pengikutsertaan paradigma keberlanjutan (sustainability), yang tidak hanya bertumpu pada peningkatan produktivitas tetapi juga memperhitungkan daya dukung alam yang semakin terdegradasi oleh pertanian modern. Di Indonesia, pertanian ramah lingkungan telah menjadi landasan pertanian mengingat tingginya peran budaya yang kaya akan kearifan lokal dalam gaya bertani penduduk Indonesia. Hanya saja, paradigma ramah lingkungan ini tereliminir sejak penerapan modernisasi pertanian yang diawali oleh gerakan Revolusi Hijau pada masa awal orde baru hingga masa reformasi (Booth, 1989; MacRae, 2005; Nordholt, 2011; Nugraha, 2015; Pedersen, 2007).

Selama lebih dari 20 tahun pertanian di Indonesia dibangun dan diarahkan dengan cara top-down, kurang memberikan ruang untuk inovasi sehingga menyebabkan stagnansi dan homogenisasi gaya bertani. Secara sosial, hal tersebut juga secara tidak langsung berdampak pada rendahnya tingkat regenerasi petani di Indonesia. Pasca reformasi, sifat suppresif dari pemerintahan mulai melemah, membuka pintu yang lebih lebar bagi globalisasi, sehingga berdampak pada ramainya kemunculan pergerakan-pergerakan berbasis komunitas di Indonesia (Reuter, 2009). Kondisi ini juga terjadi pada bidang pertanian di Indonesia, di mana aspek-aspek lokalitas yang sempat tertutup oleh superioritas pemerintah mulai tumbuh dan berkembang, menciptakan kantung-kantung produksi (production niches) yang sarat akan kearifan lokal dalam gaya bertaninya.

Pertanian ramah lingkungan pada dasarnya berarti pertanian yang menghindarkan bahan kimia dan pupuk yang bersifat meracuni lingkungan dengan tujuan untuk memperoleh kondisi lingkungan yang sehat. Selain itu, pertanian ramah lingkungan juga menghasilkan produksi tanaman yang berkelanjutan dengan cara memperbaiki kesuburan tanah menggunakan sumber 
daya alami. Pengelolaan pertanian ramah lingkungan didasarkan pada prinsip kesehatan, ekologi, keadilan, dan perlindungan.

Adanya pengembangan ilmu pengetahuan serta teknologi dalam sektor pertanian menuntut Kementerian Pertanian untuk segera bergerak melakukan perubahan dalam cara berusahatani, baik berbasis agribisnis maupun agroindustri yang keduanya mampu bersaing dengan negara lain. Maka, salah satu upaya yang dilakukan oleh Kementerian Pertanian yaitu memperkuat perbenihan, penyediaan sarana produksi, penguatan infrastruktur, serta mekanisme dalam sektor pertanian. Didukung dengan hal tersebut, maka arah regenerasi petani harus mampu untuk mendorong para petani agar lebih kreatif dan inovatif dalam mengembangkan teknologi pertanian sehingga dapat bersaing dengan negara lain dan mampu menjadi agen perubahan pembangunan pertanian secara keberlanjutan. Pencapaian dalam Gerakan Regenerasi dapat dilakukan dengan berlandaskan prinsip-prinsip pemberdayaan melalui pendekatan, yaitu: outcome oriented, terukur, efisien, konsisten, sinergi, realistis, relevan, produktif, serta inovatif.
Arah Kebijakan Regenerasi Petani adalah "Menciptakan generasi muda petani yang berjiwa sosioagripreneur, kompeten, dan berkarakter dalam mencapai kedaulatan pangan”. Dalam rangka mencapai arah kebijakan tersebut dirumuskan Strategi Regenerasi Petani yaitu pembangunan karakter dan peningkatan kapasitas generasi muda melalui pendidikan, pelatihan, dan penyuluhan sebagai dasar tumbuhnya komitmen sumberdaya manusia pembangunan pertanian; penguatan kelembagaan petani sebagai wadah generasi muda pertanian dalam membentuk jiwa kewirausahaan; dan pengembangan jejaring dan kemitraan melalui penguatan jaringan usahatani dan jaringan informasi (Kementerian Pertanian, 2016).

Mengenai UU Pemuda Nomor 40 Tahun 2009 Pasal 1 ayat 1 yang berbunyi "Pemuda adalah warga negara Indonesia yang memasuki periode penting pertumbuhan dan perkembangan yang berusia 16 (enam belas) sampai 30 (tiga puluh) tahun". Undang-undang ini dimaksudkan untuk memperkuat posisi dan kesempatan kepada setiap warga negara yang berusia 16 sampai 30 tahun untuk mengembangkan potensi, kapasitas, aktualisasi diri, dan cita- 
Determinan Partisipasi Dan Peran Petani Muda Dalam Pengembangan Pertanian Ramah Lingkungan Di Desa Cisondari, Kecamatan Ciwidey, Kabupaten Bandung, Jawa Barat

Fitrah Rahmah Insani, Iwan Setiawan, Siska Rasiska

citanya. Di samping itu, undang-undang ini memberikan jaminan perlindungan dan kepastian hukum atas eksistensi serta aktivitas kepemudaan. Undang-undang ini juga memberikan kepastian hukum bagi pemerintah dan pemerintah daerah untuk mengintegrasikan program pelayanan kepemudaan.

Rencana Strategis Kementerian Pertanian memfokuskan untuk pembangunan dalam konsep keberlanjutan. Paradigma pembangunan pertanian berkelanjutan pada hakekatnya merupakan suatu sistem dalam pembangunan pertanian melalui pengelolaan secara optimal seluruh potensi sumber daya alam serta manusia, dan teknologi untuk menjaga agar suatu upaya terus berlangsung dan tidak mengalami kemerosotan dalam rangka meningkatkan kesejahteraan masyarakat secara keseluruhan. Maka dari itu, sumberdaya manusia yang berkualitas dan memiliki komitmen untuk membangun sektor pertanian merupakan salah satu pencapaian faktor keberhasilan pembangunan pertanian berkelanjutan (Kementerian Pertanian, 2015).

Hingga saat ini dapat diketahui bahwa masih terdapat permasalahan di bidang ketenagakerjaan pertanian, yaitu struktur demografi yang kurang menguntungkan bagi sektor pertanian antara lain petani berusia tua (lebih dari 55 tahun) yang jumlahnya semakin meningkat, sementara tenaga kerja usia muda semakin berkurang. Adanya fenomena menuanya petani (aging agriculture) serta semakin menurunnya minat tenaga kerja di sektor pertanian menambah permasalahan klasik ketenaga-kerjaan pertanian selama ini, yaitu rendahnya rata-rata tingkat pendidikan dibandingkan dengan tenaga kerja di sektor lain.

Usia produktif dibagi menjadi dua kategori yaitu usia sangat produktif 15-49 tahun, sedangkan usia kurang dari 15 tahun dan usia 50-64 tergolong sebagai tenaga kerja kurang produktif tetapi masih termasuk dalam usia kerja ${ }^{1}$. Umur petani akan mempengaruhi kemampuan fisik dan respon terhadap hal-hal yang baru dalam menjalankan usaha taninya. Selain itu, petani tua masih banyak menggunakan alat dan mesin pertanian konvensional sehingga apabila generasi muda tidak berminat untuk menjadi seorang petani maka akan sulit pula untuk membangun pertanian berkelanjutan.

\section{Menurut Kartasapoetra (1991),} petani yang berusia lanjut akan sulit

\footnotetext{
1 https://www.bps.go.id/istilah/index.html?Istilah_p age $=4$
} 
untuk diberikan pengertian yang dapat mengubah cara berfikir, cara kerja dan cara hidup. Umur petani akan mempengaruhi kemampuan fisik dan respon terhadap hal-hal yang baru dalam menjalankan usahataninya. Sebagian besar petani di Indonesia berumur sekitar 25 sampai 65 tahun, semakin muda petani, biasanya mempunyai semangat ingin mengetahui yang belum mereka ketahui. Maka dari itu, perlu adanya partisipasi petani muda untuk dalam membangun pertanian.

Banyaknya pemuda desa yang meninggalkan sektor pertanian seringkali disebabkan oleh penilaian yang rendah dan menyampingkan sektor pertanian atau dikenal dengan istilah under value. Generasi muda sekarang lebih banyak tidak memilih pertanian sebagai pekerjaan karena dianggap tidak menguntungkan bagi kehidupan, identik dengan kemiskinan, status sosial yang rendah, kotor, dan tidak bergengsi, sehingga menyebabkan generasi muda tidak tertarik pada pertanian. Sumberdaya manusia yang potensial yaitu pemuda desa lebih memilih pekerjaan yang tidak berhubungan dengan tanah dan meninggalkan lahan-lahan pertanian dengan melakukan urbanisasi ke kotakota besar karena beranggapan bahwa pekerjaan selain pertanian lebih menjamin dan memiliki status sosial yang lebih tinggi. Namun, dapat kita ketahui bahwa sektor pertanian merupakan sektor yang menjadi salah satu basis ekonomi rakyat di pedesaan dan menjadi pemenuhan kebutuhan pangan nasional. Dengan adanya hal tersebut, pertanian saat ini sangatlah mengkhawatirkan dan dibutuhkan adanya penerus dalam menjalani aktifitas pertanian, yang merupakan sebagai sumber utama atau mata pencaharian utama bagi kehidupan rakyat. Jika hal itu terus terjadi, maka bukan tidak mungkin sektor pertanian di Indonesia akan mengalami keterpurukan.

Hasil penelitian Setiawan (2015) dan laporan tahunan Dinas Pertanian Provinsi Jawa Barat menunjukkan bahwa proporsi pemuda yang bertani lebih banyak ditemukan di dataran tinggi dibandingkan di dataran rendah dan di dataran medium. Beberapa faktor pendorong atau penariknya adalah usahatani dataran tinggi lebih menjanjikan dan lebih menjamin pendapatan, lebih intensif, dan lebih ekslusif. Jika melihat karakteristik dari pertanian organik baik yang dikembangkan di dataran tinggi maupun di sawah atau padi organik maka memiliki kesamaan dengan karakteristik 
Determinan Partisipasi Dan Peran Petani Muda Dalam Pengembangan Pertanian Ramah Lingkungan Di Desa Cisondari, Kecamatan Ciwidey, Kabupaten Bandung, Jawa Barat

Fitrah Rahmah Insani, Iwan Setiawan, Siska Rasiska

yang sama dari petani dataran tinggi (ekslusif).

Namun demikian, bagi petani yang sudah ketergantungan terhadap pertanian konvensional, pertanian organik dianggap rumit, mahal, dan padat kerja, sehingga tidak efisien. Selain itu, akses terhadap sumberdaya organik terutama pupuk organik dan pestisida hayati masih sulit. Apalagi tuntutan para petani semakin praktis dan pragmatis. Paradox dengan itu, pembangun pertanian dituntut untuk berlanjut secara sosial, ekonomi, dan ekologi. Salah satu wujud keberlanjutan sosial adalah terjadinya regenerasi petani. Ada dua permasalahan yang diajukan dalam penelitian ini, yaitu faktor-faktor apa saja yang mendorong pemuda untuk berpartisipasi dalam pertanian ramah lingkungan.

Dalam pelaksanaan pembangunan partisipasi masyarakat merupakan hal yang sangat mempengaruhi keberhasilan proses pembangunan itu sendiri (Murtiyanto, 2011).

\section{METODE}

Penelitian ini menggunakan pendekatan kuantitatif (Creswell, 2003). Desain penelitian yang digunakan adalah penelitian kuantitatif. Menurut Sugiyono (2012), metode kuantitatif dapat diartikan sebagai metode penelitian yang berlandaskan pada filsafat positivisme, digunakan untuk meneliti pada populasi atau sampel tertentu, pengumpulan data menggunakan instrumen penelitian, analisis data bersifat kuantitatif/statistik, dengan tujuan untuk menguji hipotesis yang telah ditetapkan. Metode penentuan sample menggunakan teknik probability sampling dengan metode simple random sampling. Menurut Sugiyono (2012), Simple Random Sampling adalah pengambilan anggota sampel dari populasi yang dilakukan secara acak tanpa memperhatikan strata yang ada dalam populasi itu.

Sampel merupakan bagian dari jumlah dan karakteristik yang dimiliki oleh populasi tersebut. Maka dari itu, sampel yang diambil dari populasi benarbenar representatif (mewakili). Untuk penentuan jumlah sampel atau petani responden berdasarkan persamaan yang dikemukakan oleh Slovin dalam Husein Umar (1999) dengan rumus sebagai berikut:

$n=\frac{N}{1+N(\lambda)^{2}}$

Keterangan:

$\mathrm{n}=$ JumlahSampel

$\mathrm{N}=$ Jumlah Populasi 
$\lambda=$ Persen kelonggaran ketidaktelitian karena pengambilan sampel yang dapat ditolelir (15\%)

$$
\mathrm{n}=\frac{332}{1+332(15 \%)^{2}}=\frac{332}{8.47}=39
$$

Berdasarkan rumus tersebut dan dengan jumlah populasi sebanyak 332 orangdi Desa Cisondari Kecamatan Pasirjambu Kabupaten bandung, maka diperoleh jumlah sampel responden sebanyak 39 orang petani. Selain responden, informasi juga akan digali dari informan pelaku muda pertanian ramah lingkungan.

Analisis statistik yang akan digunakan dalam penelitian ini adalah regresi linier berganda. Regresi linear berganda ditujukan untuk menentukan hubungan linear antar beberapa variabel bebas yang biasa disebut $\mathrm{X}_{1}, \mathrm{X}_{2}, \mathrm{X}_{3}$, dan seterusnya dengan variabel terikat yang disebut Y (Situmorang, 2008). Model persamaannya adalah sebagai berikut:

$$
Y=a+b_{1} X_{1}+b_{2} X_{2}+b_{3} X_{3}+e
$$

Keterangan :

$\mathrm{Y}=$ Variabel dependen (nilai yang diprediksikan)

$\mathrm{a}=$ Konstanta

$\mathrm{b}=$ Koefisien regresi (nilai peningkatan ataupun penurunan)

$\mathrm{X}=$ Variabel independen

$\mathrm{e}=$ Kemungkinan kesalahan

\section{Uji Asumsi Klasik}

Uji asumsi klasik dilakukan untuk memastikan bahwa model yang digunakan adalah model yang baik digunakan. Model yang baik adalah model yang mampu menjelaskan data sedekat mungkin tanpa menjadikannya rumit yang menyebabkan pemahaman terhadap data tersebut menjadi kabur atau tidak jelas (Sarwono, 2006). Dalam regresi terdapat beberapa persyaratan yang harus ditaati atau biasa disebut asumsi klasik. Uji asumsi klasik dilakukan dengan menggunakan bantuan program SPSS for Windows Version 20.0. Berikut ini adalah penjelasan mengenai pengujian asumsi klasik.

a. Uji Normalitas

Pengujian normalitas adalah pengujian tenatang kenormalan distribusi data, Idris (2010).

\section{b. Uji Multikolonieritas}

Uji multikolonieritas bertujuan untuk menguji apakah dalam model regresi ditemukan adanya korelasi antar variabel independen (Ghozali, 2011).

c. Uji Heterokedastisitas

Uji heterokedastisitas bertujuan untuk menguji apakah dalam model regresi terjadi ketidaksamaan varian dari satu pengamatan ke pengamatan yang lain (Ghozali, 2011). 
Determinan Partisipasi Dan Peran Petani Muda Dalam Pengembangan Pertanian Ramah Lingkungan Di Desa Cisondari, Kecamatan Ciwidey, Kabupaten Bandung, Jawa Barat

Fitrah Rahmah Insani, Iwan Setiawan, Siska Rasiska

2. Pengujian Hipotesis Penelitian

a. Uji Signifikansi Simultan (Uji F)

Uji F pada dasarnya menunjukan apakah semua variabel independen yang dimasukkan dalam model mempunyai pengaruh secara simultan terhadap variabel dependen. Dalam penelitian ini pengujian hipotesis secara simultan dimaksudkan untuk mengetahui adanya pengaruh variabel independen (karakteristik petani, sifat inovasi, dan faktor lingkungan) terhadap variabel dependen (tingkat partisipasi petani muda).

Hipotesis yang digunakan dalam penelitian ini adalah sebagai berikut:

- $\mathrm{H}_{0}: \beta_{1}=\beta_{2}=0$, maka variabelvariabel independen (karakteristik petani, sifat inovasi, dan faktor lingkungan) secara simultan tidak mempunyai pengaruh yang signifikan terhadap variabel dependen (tingkat partisipasi petani muda).

- $\mathrm{H}_{0}: \beta_{1}=\beta_{2} \neq 0$, maka variabelvariabel independen (karakteristik petani, sifat inovasi, dan faktor lingkungan) secara simultan mempunyai pengaruh yang signifikan terhadap variabel dependen (tingkat partisipasi petani muda).

- Dengan membandingkan nilai F hitung dengan $\mathrm{F}$ tabel
Apabila $\mathrm{F}$ tabel $>\mathrm{F}$ hitung, maka $\mathrm{H}_{0}$ diterima dan $\mathrm{H}_{1}$ ditolak, apabila $\mathrm{F}$ tabel $<\mathrm{F}$ hitung, maka $\mathrm{H}_{0}$ ditolak dan $\mathrm{H}_{1}$ diterima.

- Dengan menggunakan angka probabilitas signifikansi

Apabila probabilitas signifikansi > 0,05, maka $\mathrm{H}_{0}$ diterima dan $\mathrm{H}_{1}$ ditolak, apabila probabilitas signifikansi $<0,05$ maka $\mathrm{H}_{0}$ ditolak dan $\mathrm{H}_{1}$ diterima.

b. Uji Signifikansi Parsial (Uji t)

Uji $\mathrm{t}$ pada dasarnya menunjukan sebarapa jauh pengaruh satu variabel independen secara individual dalam menerangkan variasi variabel dependen. Pengujian ini bertujuan untuk menguji apakah terdapat pengaruh variabel independen (karakteristik petani, sifat inovasi, dan faktor lingkungan) terhadap variabel dependen (tingkat partisipasi petani muda) secara terpisah atau parsial.

Dasar pengambilan keputusan:

- Dengan membandingkan nilai $t$ hitungnya dengan $t$ tabel.

Apabila $\mathrm{t}$ tabel $>\mathrm{t}$ hitung, maka $\mathrm{H} 0$ diterima dan $\mathrm{H} 1$ ditolak. Apabila $\mathrm{t}$ tabel $<\mathrm{t}$ hitung, maka H0 ditolak dan $\mathrm{H} 1$ diterima.

- Dengan menggunakan angka probabilitas signifikansi

Apabila angka probabilitas signifikansi > 0,05, maka Ho diterima 
dan H1 ditolak. Apabila angka probabilitas signifikansi $<0,05$, maka $\mathrm{H} 0$ ditolak dan $\mathrm{H} 1$ diterima.

3. Koefisien Determinasi $\left(\mathrm{R}^{2}\right)$

Menurut Sarwono (2005), koefisien determinasi digunakan untuk menghitung besarnya peranan atau pengaruh variabel independen (X) terhadap variabel dependen (Y). Koefisien determinasi dihitung dengan cara mengkuadratkan hasil korelasi kemudian dikalikan dengan 100\%. Adapun rumus untuk mendapatkan koefisien determinasi adalah sebagai berikut:

$$
\mathrm{Kd}=\mathbf{r}_{\mathrm{xy}}^{2} \times 100 \%
$$

Keterangan:

$\mathrm{Kd}=$ Koefisien determinasi

rxy $=$ Koefisien korelasi

\section{HASIL DAN PEMBAHASAN}

\section{Determinan Partisipasi Petani Muda}

Analisis regresi linier berganda diigunakan dalam penelitian ini dengan tujuan untuk membuktikan hipotesis mengenai adanya pengaruh parsial dan ditolak pada karakteristik petani $\left(\mathrm{X}_{1}\right)$, sifat inovasi $\left(\mathrm{X}_{2}\right)$, dan faktor lingkungan $\left(\mathrm{X}_{3}\right)$ terhadap partisipasi petani muda dalam program pertanian ramah lingkungan. Analisis ini dibantu dengan menggunakan program SPSS for
Windows vesion 20.0. Berikut ini adalah hasil dari pengolahan data:

1. Uji Asumsi Klasik

a. Uji Normalitas

Gambar 1 menunjukkan bahwa grafik normal probability plot menunjukkan bahwa terlihat data menyebar di sekitar garis diagonal dan mengikuti arah garis diagonal.

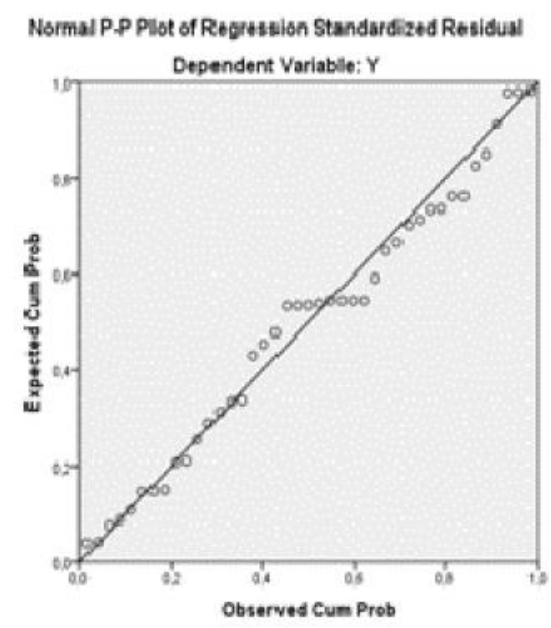

Gambar 1. Grafik Normal Probability Plot

Maka dapat dikatakan bahwa grafik tersebut sudah memenuhi syarat untuk prediksi partisipasi petani muda dalam program pertanian ramah lingkungan $(\mathrm{Y})$ berdasarkan data karakteristik petani $\left(\mathrm{X}_{1}\right)$, sifat inovasi $\left(\mathrm{X}_{2}\right)$, faktor lingkungan $\left(\mathrm{X}_{3}\right)$ yang dapat disebut memiliki distribusi normal. Oleh karena itu, dapat disimpulkan model regresi berganda yang digunakan memenuhi asumsi normalitas. 
Determinan Partisipasi Dan Peran Petani Muda Dalam Pengembangan Pertanian Ramah Lingkungan Di Desa Cisondari, Kecamatan Ciwidey, Kabupaten Bandung, Jawa Barat

Fitrah Rahmah Insani, Iwan Setiawan, Siska Rasiska

b. Uji Asumsi Multikolinieritas

Uji multikolinieritas dilakukan dengan mencari nilai VIF (Variance Inflation Factor) dan tolerance dari variabel karakteristik petani, sifat inovasi, dan faktor lingkungan yang didapatkan.

Tabel 1. Nilai Tolerance dan VIF

\begin{tabular}{lll}
\hline Variabel & Tolerance & VIF \\
\hline $\begin{array}{l}\text { Karakteristik } \\
\text { Petani }\end{array}$ & 0,571 & 1,751 \\
\hline Sifat Inovasi & 0,614 & 1,630 \\
\hline $\begin{array}{l}\text { Faktor } \\
\text { Lingkungan }\end{array}$ & 0,903 & 1,108 \\
\hline
\end{tabular}

Berdasarkan Tabel 1 dapat dilihat bahwa tidak ada variabel independen yang memiliki nilai VIF lebih besar dari 10 dan nilai tolerance kurang dari 0,10 . Maka dari itu, hal ini menunjukkan bahwa tidak terdapat korelasi antara variabel karakteristik petani, sifat inovasi, dan faktor lingkungan dalm model regresi linier berganda yang digunakan.

c. Uji Heterokedastisitas

Berikut adalah hasil uji heterokedastisitas yang dilakukan.

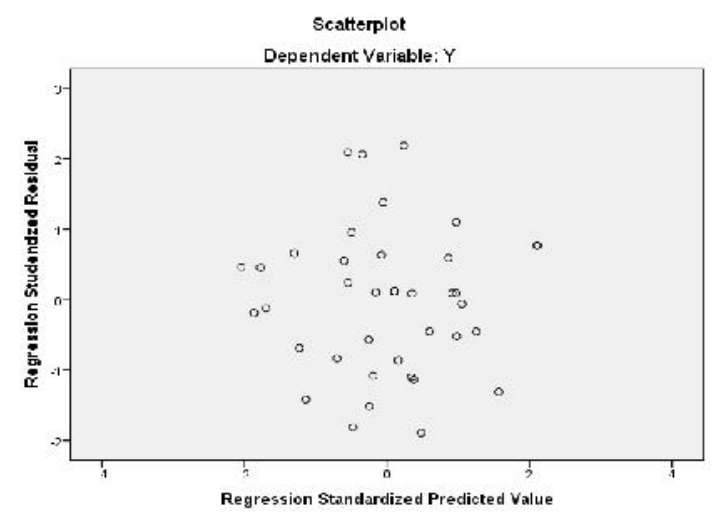

\section{Gambar 1. Grafik Scatterplot}

Gambar 2 menunjukkan bahwa titik-titik menyebar secara acak serta tersebar baik di atas maupun di bawah angka 0 pada sumbu Y. Oleh karena itu, disimpulkan bahwa tidak terjadi heterokedastisitas atau tidak terjadi ketidaksamaan varian dari satu pengamatan ke pengamatan lain pada model regresi berganda yang digunakan.

2. Analisis Regresi Linier Berganda

a. Uji Hipotesis

1) Uji Simultan (Uji F)

Berikut hasil pengujian uji $\mathrm{F}$.

\section{Tabel 2. Hasil Uji F}

ANOVA $^{\text {a }}$

\begin{tabular}{|c|c|c|c|c|}
\hline Model & $\begin{array}{l}\text { Sum of } \\
\text { Squares }\end{array} \mid \mathrm{df}$ & $\begin{array}{l}\text { Mean } \\
\text { Square }\end{array}$ & $F$ & Sig. \\
\hline $\begin{array}{l}\text { Regression } \\
1 \text { Residual } \\
\text { Total }\end{array}$ & \begin{tabular}{|l|l|}
2878,118 & 3 \\
2268,284 & 37 \\
5146,402 & 40
\end{tabular} & $\begin{array}{l}959,373 \\
61,305\end{array}$ & 15,649 & $9,000^{b}$ \\
\hline
\end{tabular}

a. Dependent Variable: Y (Tingkat Partisipasi)

b. Predictors: (Constant), (X3) Faktor Lingkungan, (X2) Sifat Inovasi, ( X1) Karakteristik Petani 
Tabel 2 menunjukkan bahwa berdasarkan hasil uji $\mathrm{F}$ didapatkan nilai $F_{\text {hitung sebesar 15,649 dengan probabilitas }}$ signifikansi 0,000. Karena angka tersebut lebih kecil dari 0,05 dan Fhitung lebih besar dari Ftabel, maka diputuskan bahwa variabel karakteristik petani (X1), sifat inovasi (X2), faktor lingkungan (X3) secara simultan memiliki pengaruh yang signifikan terhadap tingkat partisipasi (Y).

\section{2) Uji Parsial (Uji t)}

Berikut adalah hasil pengujian uji t.

\section{Tabel 3. Hasil Uji t}

\begin{tabular}{|l|l|l|l|l|}
\hline Model & T hitung & $t$ t tabel & Sig. & $\alpha$ \\
\hline & & 0,026 & & 0,05 \\
$\begin{array}{l}\text { Karakteristik } \\
\text { Petani }\end{array}$ & 2,937 &, 006 & \\
$\begin{array}{l}\text { Sifat Inovasi } \\
\text { Faktor } \\
\text { Lingkungan }\end{array}$ & 2,294 &, 028 & \\
\hline
\end{tabular}

Tabel 3 menujukkan bahwa hasil uji hipotesis secara parsial menggunakan

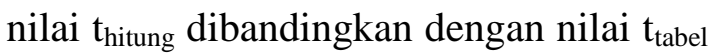
adalah sebagai berikut.

a) Pengaruh karakteristik petani terhadap tingkat partisipasi petani muda

Pada tabel tersebut diketahui bahwa karakteristik petani $\left(\mathrm{X}_{1}\right)$ memiliki nilai $t_{\text {hitung }}$ sebesar 2,937 dengan probabilitas signifikansi 0,005 . Nilai $t_{\text {tabel }}$ adalah sebesar 2,026 dengan tingkat signifikansi 0,05 . Maka dengan demikian nilai $t_{\text {hitung }}=$ $2,937>$ nilai $t_{\text {tabel }}=2,026$ dan angka probabilitas signifikansi $0,005<0,05$ sehingga keputusannya adalah $\mathrm{H}_{0}$ ditolak dan $\mathrm{H}_{1}$ diterima.

b) Pengaruh sifat inovasi terhadap tingkat partisipasi petani muda

Pada tabel tersebut diketahui bahwa sifat inovasi $\left(\mathrm{X}_{2}\right)$ memiliki nilai $\mathrm{t}_{\text {hitung }}$ sebesar 2,294 dengan probabilitas signifikansi 0,028. Nilai $t_{\text {tabel }}$ adalah sebesar 2,026 dengan tingkat signifikansi 0,05 . Maka dengan demikian nilai $t_{\text {hitung }}=$ $2,294>$ nilai $t_{\text {tabel }}=2,026$ dan angka probabilitas signifikansi $0,028<0,05$ sehingga keputusannya adalah $\mathrm{H}_{0}$ ditolak dan $\mathrm{H}_{1}$ diterima.

c) Pengaruh faktor lingkungan terhadap tingkat partisipasi petani muda

Pada tabel tersebut diketahui bahwa faktor lingkungan $\left(\mathrm{X}_{3}\right)$ memiliki nilai $t_{\text {hitung }}$ sebesar 1,673 dengan probabilitas signifikansi 0,103. Nilai $t_{\text {tabel }}$ adalah sebesar 2,026 dengan tingkat signifikansi 0,05 . Maka dengan demikian nilai $t_{\text {hitung }}=$ $1,673<$ nilai $\mathrm{t}_{\text {tabel }}=2,026$ dan angka probabilitas signifikansi $0,103>0,05$ sehingga keputusannya adalah $\mathrm{H}_{0}$ diterima dan $\mathrm{H}_{1}$ ditolak. 
Determinan Partisipasi Dan Peran Petani Muda Dalam Pengembangan Pertanian Ramah Lingkungan Di Desa Cisondari, Kecamatan Ciwidey, Kabupaten Bandung, Jawa Barat

Fitrah Rahmah Insani, Iwan Setiawan, Siska Rasiska

b. Persamaan Regresi Linier Berganda

Pada hasil analisis data dengan bantuan program SPSS for Windows version 20.0. Berikut merupakan hasil penghitungan yang diperoleh persamaan regresi berganda berdasarkan output.

Tabel 4. Regresi Linier Berganda

Coefficients $^{\mathrm{a}}$

\begin{tabular}{|c|c|c|c|c|c|c|}
\hline \multirow{3}{*}{ Model } & \multirow{2}{*}{\multicolumn{2}{|c|}{\begin{tabular}{|l} 
Unstandardized \\
Coefficients
\end{tabular}}} & \multirow{3}{*}{\begin{tabular}{|l} 
Standardized \\
Coefficients \\
Beta
\end{tabular}} & & Sig. 9 & Koefisien Determinasi $\left(\mathrm{R}^{2}\right)$ \\
\hline & & & & & & \\
\hline & B & Std. Error & & & & Koefisien \\
\hline (Constant) & $-13,911$ & 9,493 & & $-1,465$ & & ertujuan untuk mengukur sejauh ma \\
\hline $\mathrm{X} 1$ & 1,400 & ,477 & 424 & 2,937 &, 006 & \\
\hline $\mathrm{X} 2$ & 665 &, 290 & 320 & 2,294 & 028 & \\
\hline $\mathrm{X} 3$ &, 206 & 1,123 & 192 & 1,673 & 103 & den. Nilai ko \\
\hline
\end{tabular}

Output yang didapat berdasarkan tabel diatas adalah:

$Y=a+\beta_{1} X_{1}+\beta_{2} X_{2}+\beta_{3} X_{3}+\varepsilon$

$\mathrm{Y}=-13.911+1.400 \mathrm{X}_{1}+0.665 \mathrm{X}_{2}+$ $0,206 X_{3}+\varepsilon$

Persamaan di atas berarti:

1. Jika karakteristik petani, sifat inovasi, dan faktor lingkungan bernilai nol, maka tingkat partisipasi petani muda bernilai $-13,911$.

2. Jika karakteristik petani meningkat 1 satuan maka akan menurunkan tingkat partisipasi petani muda bernilai 1,400 dengan asumsi sifat inovasi dan faktor lingkungan bernilai konstan.

3. Jika sifat inovasi meningkat 1 satuan maka akan meningkatkan tingkat partisipasi petani muda berniali 0,665 dengan asumsi karakteristik petani dan faktor lingkungan bernilai konstan.

4. Jika faktor lingkungan meningkat 1 satuan maka akan meningkatkan tingkat partisipasi petani muda bernilai 0,206 dengan asumsi karakteristik dan sifat inovasi bernilai konstan.

determinasi adalah antara nol dan satu, dimana nilai yang mendekati satu berarti bahwa variabel independen yang digunakan memberikan hampir semua informasi yang diperlukan untuk mempengaruhi variabel dependen. Hasil analisis data dengan bantuan program SPSS for Windows version 20.0. Berikut merupakan hasil penghitungan yang diperoleh koefisien determinasi berdasarkan output.

\section{Tabel 5. Hasil Koefisien Determinasi}

Model Summary ${ }^{b}$

\begin{tabular}{|l|l|l|l|l|}
\hline Model & R & $\begin{array}{l}\text { R } \\
\text { Square }\end{array}$ & $\begin{array}{l}\text { Adjusted R } \\
\text { Square }\end{array}$ & $\begin{array}{l}\text { Std. Error } \\
\text { of the } \\
\text { Estimate }\end{array}$ \\
\hline 1 &, $748^{\mathrm{a}}$ &, 559 &, 524 & 7,82975 \\
\hline
\end{tabular}

Tabel 5 menunjukkan diperoleh nilai koefisien korelasi berganda antara 
karakteristik petani, sifat inovasi, dan faktor lingkungan yang mempengaruhi tingkat partisipasi petani muda adalah 0,748. Hal itu menunjukkan bahwa hubungan yang

$\mathrm{KD}=\mathrm{r}^{2} \times 100 \%=(0.748)^{2} \times 100 \%=$ $0.559 \times 100 \%=55.9 \%$

Menurut hasil perhitungan di atas, maka dapat diketahui bahwa koefisien determinasinya adalah $55.9 \%$ yang berarti tingkat partisipasi petani muda dengan persentase $55.9 \%$ ditentukan oleh karakteristik petani, sifat inovasi, dan faktor lingkungan yang mempengaruhi tingkat partisipasi petani muda. Sedangkan sisanya $43.4 \%$ dipengaruhi oleh variabel lain yang tidak diteliti.

d. Faktor yang paling mempengaruhi tingkat partisipasi petani muda

Beberapa faktor yang dapat diketahui bahwa variabel tersebut berpengaruh terhadap tingkat partisipasi petani muda. Setelah dihitung terlebih dahulu, maka nilai korelasi dapat dilihat pada Tabel 6.

Tabel 6 menunjukkan bahwa nilai korelasi antara karakteristik petani dengan tingkat partisipasi petani muda adalah sebesar 0,682 , korelasi antara sifat inovasi dengan tingkat partisipasi petani muda adalah sebesar 0,616, korelasi antara faktor lingkungan dengan tingkat partisipasi petani muda adalah sebesar 0,379 .

\section{Tabel 6. Korelasi Antar Variabel}

\begin{tabular}{|c|c|c|c|c|c|}
\hline \multicolumn{6}{|c|}{ Correlations } \\
\hline & & $\mathrm{X} 1$ & $\mathrm{X} 2$ & X3 & $\mathrm{Y}$ \\
\hline \multirow{4}{*}{ X1 } & Pearson & 1 & $621^{* *}$ &, $311^{*}$ & $682^{* *}$ \\
\hline & Correlation & & 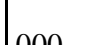 & 048 & 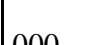 \\
\hline & Sig. (2-tailed) & & & |,048 & ,000 \\
\hline & $\mathrm{N}$ & 41 & 41 & 41 & 41 \\
\hline \multirow{3}{*}{$\mathrm{X} 2$} & Pearson & $621^{* *}$ & 1 &, 172 &, $616^{* *}$ \\
\hline & Sig. (2-tailed) & 000 & & ,282 & ,000 \\
\hline & $\mathrm{N}$ & 41 & 41 & 41 & 41 \\
\hline \multirow{3}{*}{ X3 } & $\begin{array}{l}\text { Pearson } \\
\text { Correlation }\end{array}$ & $311^{*}$ & 172 & 1 &, $379^{*}$ \\
\hline & Sig. (2-tailed) & 048 &, 282 & &, 015 \\
\hline & $\mathrm{N}$ & 41 & 41 & 41 & 41 \\
\hline \multirow{3}{*}{$\mathrm{Y}$} & $\begin{array}{l}\text { Pearson } \\
\text { Correlation }\end{array}$ & $682^{* *}$ & $616^{* *}$ &, $379^{*}$ & 1 \\
\hline & Sig. (2-tailed) &, 000 &, 000 &, 015 & \\
\hline & $\mathrm{N}$ & 41 & 41 & 41 & 41 \\
\hline
\end{tabular}

Kemudian, dapat diketahui bahwa hasil analisis nilai koefisien regresi yang sudah terstandarisasi. Menurut hasil analisis, dapat dihitung kontribusi masing-masing variabel sebagai berikut:

1. Kontribusi variabel karakteristik petani $\left(\mathrm{X}_{1}\right)=$ Standardized Coefficients regresi $X_{1}$ dikalikan korelasi $\mathrm{Y}$ dan $\mathrm{X}_{1}=0,682 \times 0,424=$ 0,289

2. Kontribusi variabel sifat inovasi $\left(\mathrm{X}_{2}\right)$ $=$ Standardized Coefficients regresi $\mathrm{X}_{2}$ dikalikan korelasi $\mathrm{Y}$ dan $\mathrm{X}_{2}=$ $0,616 \times 0,320=0.197$

3. Kontribusi variabel faktor lingkungan $\left(\mathrm{X}_{3}\right)=$ Standardized Coefficients regresi $\mathrm{X}_{3}$ dikalikan korelasi $\mathrm{Y}$ dan $\mathrm{X}_{3}$ $=0,379 \times 0,192=0,072$

4. Total $=0,289+0,197+0,072=0,556$ 
Determinan Partisipasi Dan Peran Petani Muda Dalam Pengembangan Pertanian Ramah Lingkungan Di Desa Cisondari, Kecamatan Ciwidey, Kabupaten Bandung, Jawa Barat

Fitrah Rahmah Insani, Iwan Setiawan, Siska Rasiska

Berdasarkan hasil perhitungan yang sudah dilakukan diatas, maka dapat diketahui faktor yang paling berpengaruh terhadap tingkat partisipasi petani muda adalah karakteristik petani $\left(\mathrm{X}_{1}\right)$ karena memiliki kontribusi yang paling besar.

e. Pembahasan atas Hasil Analisis Statistik

Secara umum, berdasarkan hasil analisis statistik dapat ditegaskan bahwa untuk meningkatkan partisipasi petani muda dalam pertanian ramah lingkungan hanya memperhatikan karakteristik petani (terutama aspek motivasi dan prasyarat) yang didukung dengan adanya faktor yang mempengaruhi seperti motivasi dan prasyarat untuk berpartisipasi karena hal itu terjadi pada saat petani muda membentuk suatu sikap terhadap program partisipasi pertanian ramah lingkungan. Sifat inovasi (terutama aspek keuntungan relatif, kompabilitas, kompleksitas, triabilitas, dan observabilitas) mempengaruhi dengan bagaimana pandangan petani terhadap keuntungan dari pertanian ramah lingkungan secara ekonomis dibandingkan dengan teknik konvensional, selain itu adanya kesesuaian akan lingkungan yang sehat, serta teknik pertanian ramah lingkungan mudah dimengerti dan diterapkan pada lahan usahatani (Fardiaz, 2008). Faktor lingkungan (terutama aspek informasi, kelompok tani, teknologi informasi, penyuluhan, sosial budaya, alam, pasar, dan kebijakan) dilihat dari lingkungan petani yang berpengaruh yaitu berupa informasi dengan para petani muda lain mengadakan diskusi dan mengikuti budaya di daerah tersebut, serta pasar yang lebih luas dan menguntungkan untuk para petani. Sehingga dapat dikatakan bahwa pertanian ramah lingkungan dapat terus dikembangkan dengan adanya petani muda untuk ikut serta berpartisipasi (Panurat, 2014).

\section{KESIMPULAN}

Pada uraian diatas yang telah disajikan sebelumnya, maka kesimpulan yang dapat diambil adalah variabel karakteristik petani, sifat inovasi, dan faktor lingkungan memiliki pengaruh terhadap tingkat partisipasi petani muda. Hal tersebut berarti bahwa seberapa tinggi tingkat karakteristik petani, sifat inovasi, dan faktor lingkungan dapat memberikan pengaruh terhadap tingkat partsipasi yang dilakukan oleh petani muda.

1. Partisipasi yang dilakukan oleh petani muda yaitu ada pada dalam tahap perencanaan yang berupa penyusunan program pertanian ramah lingkungan, 
pelaksanaan dalam menjalankan program, monitoring pada saat kegiatan dilaksanakan dan evaluasi pada saat kegiatan telah berlangsung, pemanfaatan hasil seperti adanya keuntungan yang dirasakan seperti lebih hemat input, sehat, bersih, serta tipe partisipasi yang dimiliki oleh petani muda di Desa Cisondari. Para petani muda di Desa Cisondari ikut berpartisipasi dalam bentuk pembuatan pestisida nabati serta memasarkan produk ke supermarket dan saat ini sedang berusaha untuk menjual produk secara online.

2. Faktor-faktor yang mempengaruhi partisipasi petani muda dalam program pertanian ramah lingkungan adalah:

a. Karakteristik petani menjadi pengaruh yang paling dominan dalam tingkat partisipasi petani muda pada program pertanian ramah lingkungan. Keadaan tersebut menegaskan bahwa adanya motivasi yang ada pada jiwa para petani muda tersebut dapat memberikan nilai semangat agar terus ikut serta berpartisipasi. Selain itu, petani muda juga selalu ada kemauan, kesempatan, dan kemampuan untuk ikut berpartisipasi. b. Sifat inovasi dapat dikatakan sebagai pengaruh dalam tingkat partisipasi petani muda pada program pertanian ramah lingkungan. Hal tersebut dikarenakan adanya sebab seperti keuntungan yang didapat oleh para petani muda serta pertanian ramah lingkungan mudah untuk dilakukan. Dapat dibuktikan bahwa petani muda di Desa Cisondari membuat pestisida nabati yang buat oleh mereka sendiri lalu diperjual belikan.

c. Faktor lingkungan menjadi salah satu faktor pendukung yang mempengaruhi tingkat partisipasi petani muda pada program pertanian ramah lingkungan. Petani muda di Desa Cisondari memerlukan sharing secara berkelanjutan untuk terus menerapkan dan memajukan program pertanian ramah lingkungan. Selain itu hal tersebut didukung pula karena wilayahnya yang berada di pegunungan serta kebijakan dari pemerintah untuk menerapkan pertanian ramah lingkungan.

Berdasarkan hasil dan kesimpulan yang telah disajikan, maka ada beberapa saran-saran, yaitu:

1. Petani muda di Desa Cisondari perlu untuk tetap mempertahankan karakteristik petani, sifat inovasi, dan 
Determinan Partisipasi Dan Peran Petani Muda Dalam Pengembangan Pertanian Ramah Lingkungan Di Desa Cisondari, Kecamatan Ciwidey, Kabupaten Bandung, Jawa Barat

Fitrah Rahmah Insani, Iwan Setiawan, Siska Rasiska

faktor lingkungan pada tingkat partisipasi dalam program pertanian ramah lingkungan. Selain itu, petani muda di Desa Cisondari perlu mengajak para pemuda lainnya agar adanya tambahan penerus petanipetani muda.

2. Dalam hasil analisis statistik, ada $43,4 \%$ mengenai variabel yang belum diteliti. Maka dari itu, perlu adanya penelitian lebih lanjut mengenai faktor apa lagi yang mempengaruhi tingkat partisipasi petani muda dalam program pertanian ramah lingkungan.

\section{DAFTAR PUSTAKA}

Booth, A. (1989). Indonesian agricultural development in comparative perspective. World Development, 17(8), 1235-1254. https://doi.org/10.1016/0305750X(89)90235-0

Creswell, J. W. (2003). Creswell, J.W. (2003). One, "A Framework for Design." Research Design Qualitative Quantitative and Mixed Methods Approaches, 3-26. https://doi.org/10.3109/08941939.2 012.723954

Kementerian Pertanian. 2015. Analisis PDB Sektor Pertanian Tahun 2015. Jakarta: Pusat Data dan Sistem Informasi Pertanian Sekretarian Jenderal, Kementerian Pertanian.

Kementerian Pertanian. 2016. Rencana Strategis 2015-2019. Badan Penyuluhan dan Pengembangan Sumber Daya Manusia Pertanian.

Kementerian Pertanian. 2015. Rencana Strategis Kementerian Pertanian.
Jakarta.

MacRae, G. (2005). Negara Ubud: The Theatre state in Twenty first century Bali. History and Anthropology, 16(4), 393-413. https://doi.org/10.1080/0275720050 0344616

Nordholt, H. (2011). Indonesia in the 1950s: Nation, modernity, and the post-colonial state. Bijdragen Tot de Taal-, Land-En Volkenkunde, 167(4), 386-404. Retrieved from http://www.jstor.org/stable/413290 00

Nugraha, A. (2015). An ethnography study of farming style in Gianyar , Bali , Indonesia.

Pedersen, L. (2007). Responding to Decentralisation in the Aftermath of the Bali Bombing. The Asia Pacific Journal of Anthropology. Retrieved from http://www.tandfonline.com/doi/ab s/10.1080/14442210701519805

Reuter, T. (2009). Globalisation and Local Identities: The Rise of New Ethnic and Religious Movements in Post-Suharto Indonesia. Asian Journal of Social Science, 37(6), 857-871.

https://doi.org/10.1163/156848409 X12526657425181

Sarwono, Jonathan. 2006. Metode Penelitian Kuantitatif dan Kualitatif. Yogyakarta: Graha Ilmu.

Setiawan, I., 2012. Agribisnis kreatif: pilar wirausaha masa depan, kekuatan dunia baru menuju kemakmuran hijau. Penebar Swadaya Grup.

Sugiyono. 2012. Metode Penelitian Kuantitatif Kualitatif dan $R \& D$. Yogyakarta. Penerbit Alfabeta. 